\title{
Acetylcholinesterase sensor based on screen-printed carbon electrode modified with prussian blue
}

Received: 28 March 2005 / Revised: 6 June 2005 / Accepted: 3 July 2005 / Published online: 15 September 2005

(C) Springer-Verlag 2005

\begin{abstract}
Acetylcholinesterase (ChE) sensor based on Prussian blue (PB) modified electrode was developed and tested for the detection of organophosphorus and carbamic pesticides. The signal of the sensor was generated in PB mediated oxidation of thiocholine recorded at $+200 \mathrm{mv}$ in DC mode. ChE from electric eel was immobilized by cross-linking with glutaraldehyde in the presence of bovine serum albumin (BSA) on the surface of screen-printed carbon electrode covered with PB and Nafion. The content of the surface layer (specific enzyme activity, Nafion and BSA amounts) was optimized to establish high and reliable response toward the substrate and $\mathrm{ChE}$ inhibitors. The $\mathrm{ChE} / \mathrm{PB}$ sensor makes it possible to detect Aldicarb, Paraoxon and Parathion-Methyl with limits of detection 30,10 and $5 \mathrm{ppb}$, respectively (incubation $10 \mathrm{~min}$ ). The feasibility of practical application of the $\mathrm{ChE} / \mathrm{PB}$ sensor developed for the monitoring of degradation of the pesticides in wine fermentation was shown. To diminish matrix interferences, the electrolysis of the grape juice with $\mathrm{Al}$ anode and evaporation of ethanol were suggested, however the procedures decrease the sensitivity of pesticide detection and stability of the sample tested.
\end{abstract}

Keywords Cholinesterase sensor - Biosensor - Pesticide detection · Prussian Blue $\cdot$ Wine contamination

Abbreviations ChE: Acetylcholinesterase PB: Prussian blue - BSA: bovin serum albumin - ChO: choline oxidase TCNQ: tetracyanoqunodimethane $\cdot$ ATCh: acetylthiocholine

\footnotetext{
E. Suprun · G. Evtugyn $(\bowtie) \cdot H$. Budnikov

Chemistry Department, Kazan State University,

18, Kremlevskaya Street,

420008 Kazan, Russia

e-mail: Gennady.Evtugyn@ksu.ru

F. Ricci · D. Moscone · G. Palleschi

Dipartimento di Scienze e Technologie Chimiche,

Università di Roma "Tor Vergata",

via della Ricerca Scientifica,

00133 Roma, Italy
}

\section{Introduction}

The development of new sensors for the fast, sensitive and reliable detection of biologically active compounds is considered to be the principal trend of modern analytical chemistry [1]. This is particularly true for electrochemical enzyme sensors based on graphite electrodes. Low cost, simple measurement procedure as well as their compatibility with conventional electrochemical equipment make enzyme sensors very attractive for routine detection of different compounds that are specific substrates or inhibitors of enzymes, among them in field. Carbon materials (glassy carbon, screenprinted thin layers and thick-film carbon paste) can be easily covered with enzymes by physical sorption followed by cross-linking with glutaraldehyde or entrapment in polymer films $[2,3]$. This procedure is commonly supplemented with the modification of a carbon surface with various additives [4]. The electrode modification reduces the working potential and increases the reversibility of electrode reactions to provide higher sensitivity and selectivity of the signal in complex media as well as its better resolution in the presence of electrochemically active components [5]. For this purpose, heterogeneous mediators of electron transfer, e.g. insoluble salts and complexes of transient metals [5-7], electroconductive polymers $[5,8,9]$, organometallic and heteroaromatic compounds $[10,11]$ are generally used.

Prussian Blue (ferric hexacyanoferrate, PB), has been extensively investigated during the last decade due to its efficient mediation of the cathodic reduction of $\mathrm{H}_{2} \mathrm{O}_{2}[6$, $12-14]$. For this reason, PB modified electrodes were successfully used in assembling enzyme sensors based on redox enzymes producing $\mathrm{H}_{2} \mathrm{O}_{2}$ in the selective conversions of the substrates. Thus, the PB detection of the signals referring to glucose oxidase $[15,16]$, cytochrome $c$ [17], cholesterol oxidase [18] and choline oxidase [19] has been described. In addition to the $\mathrm{H}_{2} \mathrm{O}_{2}$ reduction, $\mathrm{PB}$ modified electrodes were applied for the electrochemical determination of ascorbic acid [20], hydrazine [21, 22] and thiols $[23,24]$. PB differs favorably from many other modifiers applied in enzyme sensors by the high efficiency of electron transfer $\left(\mathrm{E}^{0}\right.$ about $0.0 \mathrm{~V}$ vs. $\left.\mathrm{Ag} / \mathrm{AgCl}\right)$ in a wide $\mathrm{pH}$ 
range, by the stability of its electrochemical characteristics and the simple procedure for depositing and activating.

Previously, we have proved the advantages of $\mathrm{PB}$ as a mediator in assembling the acetylcholinesterase (ChE)choline oxidase $(\mathrm{ChO})$ bi-enzyme sensor developed for the detection of organophosphorus and carbamic pesticides [19]. Both enzymes were co-immobilized on the working area of the screen-printed electrode covered with PB. The cathodic current of the $\mathrm{PB}$ mediated $\mathrm{H}_{2} \mathrm{O}_{2}$ reduction was recorded in an amperometric mode as a measure of the acetylcholine concentration and activity of ChE (1).

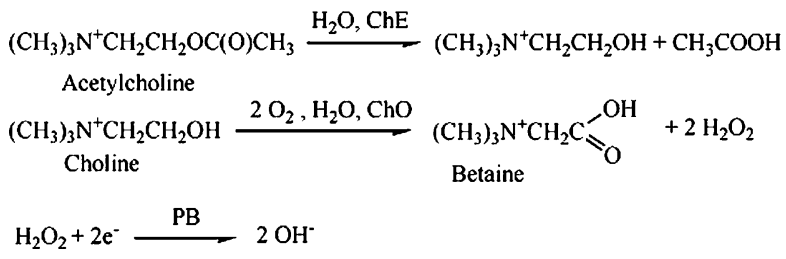

In comparison with non-modified sensors and screenprinted electrodes with $7,7^{\prime}, 8,8^{\prime}$-tetracyanoquinodimethane (TCNQ) introduced into the carbon paste, ChE-ChO-PB amperometric sensor showed a faster response $(0.3$ and about $3 \mathrm{~min}$, respectively) and a lower working potential ( $+50 \mathrm{mV}$ against $+560 \mathrm{mV}$ vs. $\mathrm{Ag} / \mathrm{AgCl}$ for non-mediated electron transfer).

The optimization of the ChE-ChO sensor is often complicated due to problems related to the conjugation of two enzymatic processes, i.e. the difference in the $\mathrm{pH}$ maximum and the specific activities of the enzymes. For this reason, the interest for the development of the monoenzyme $\mathrm{ChE}$ sensor with improved analytical and operational characteristics has been emphasized. Even though the products of the $\mathrm{ChE}$ hydrolysis of acetylcholine are electrochemically inactive, the measurement of $\mathrm{ChE}$ activity can be performed with thiocholine ethers as a $\mathrm{ChE}$ synthetic substrate. However, direct oxidation of thiocholine (2) requires high working potentials (up to $+680 \mathrm{mV}$ ) $[25,26]$ and is often complicated with electrode poisoning.

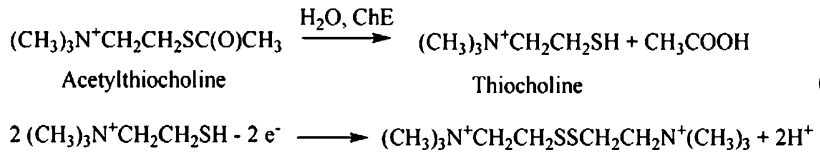

These complications can be avoided by including mediators, e.g. Co phtalocyanine [27, 28] or TCNQ [29] into the sensor material. Recently, we have also demonstrated the possibility of direct non-enzymatic oxidation of thiocholine at the PB modified screen-printed electrode (3):

$\left(\mathrm{CH}_{3}\right)_{3} \mathrm{~N}^{+} \mathrm{CH}_{2} \mathrm{CH}_{2} \mathrm{SC}(\mathrm{O}) \mathrm{CH}_{3} \stackrel{\mathrm{H}_{2} \mathrm{O}, \mathrm{ChE}}{\longrightarrow}\left(\mathrm{CH}_{3}\right)_{3} \mathrm{~N}^{+} \mathrm{CH}_{2} \mathrm{CH}_{2} \mathrm{SH}+\mathrm{CH}_{3} \mathrm{COOH}$

$2\left(\mathrm{CH}_{3}\right)_{3} \mathrm{~N}^{+} \mathrm{CH}_{2} \mathrm{CH}_{2} \mathrm{SH}+2 \mathrm{~PB}_{0 x} \rightarrow\left(\mathrm{CH}_{3}\right)_{3} \mathrm{~N}^{+} \mathrm{CH}_{2} \mathrm{CH}_{2} \mathrm{SSCH}_{2} \mathrm{CH}_{2} \mathrm{~N}^{+}\left(\mathrm{CH}_{3}\right)_{3}+2 \mathrm{~PB}_{\text {Red }}$

$\mathrm{PB}_{\text {Red }}-2 \mathrm{e}^{-} \rightleftharpoons 2 \mathrm{~PB}_{\mathrm{Ox}}$

where $\mathrm{PB}_{\mathrm{Red}}$ and $\mathrm{PB}_{\mathrm{Ox}}$ are the reduced and oxidized forms of the mediator [24]. The prospects of PB mediated oxi- dation of thiocholine were shown by determining organophosphorus and carbamic pesticides in aqueous solutions. Their reaction with free ChE resulted in the decrease of enzyme activity followed by the reduction of the amounts of thiocholine formed. This resulted in the decay of the current generated in thiocholine/PB reaction (3) at the anode.

In this work, we proceed with the investigation of the thiocholine/PB system for the development of a ChE/PB sensor and have studied the conditions of ChE immobilization on the surface of the screen-printed electrode modified with PB and of the determination of anticholinesterase pesticides. The $\mathrm{ChE} / \mathrm{PB}$ sensor was also used for the estimation of matrix effect and pesticide degradation in wine making.

\section{Experimental}

\section{Apparatus}

The three-electrode system with $\mathrm{Ag} / \mathrm{AgCl}$ reference and Pt counter electrodes was used for the measurement of the signal of ChE/PB sensor. Cyclic voltammograms were recorded with AUTOLAB PGSTAT-12 electrochemical system with GPES software (EcoChemie Utrecht, The Netherlands). Chronoamperometric measurements were carried out with VA 641 amperometric detector (Metrohm, Herisau, Switzerland) connected with AMEL MODEL868 recorder.

\section{Reagents}

Acetylcholinesterase from electric eel (EC 3.1.1.7, 244 $\mathrm{U} / \mathrm{mg}$ ), acetylthiocholine chloride (ATCh), bovine serum albumin (BSA), glutaraldehyde, $\mathrm{FeCl}_{3} \times 6 \mathrm{H}_{2} \mathrm{O}$ were purchased from Sigma (Steinheim, Germany), Nafion (perfluorinated ion-exchange resin, 5\% w/v solution in lower alcohols/water) from Aldrich (Steinheim, Germany), $\mathrm{K}_{3} \mathrm{Fe}$ $(\mathrm{CN})_{6}, 98 \%$, from Carlo ERBA reagenti. All the other reagents used were of analytical grade (Carlo ERBA reagenti and Sigma, Steinheim, Germany). All the experiments were carried out in $0.05 \mathrm{~mol} \mathrm{~L}^{-1}$ phosphate buffer solution containing $0.1 \mathrm{mmol} \mathrm{L}^{-1} \mathrm{KCl}$. Aldicarb $(99 \%$, Riedel-de Haen, Seelze, Germany), Parathion-methyl (99.8\%, Riedel-de Haen, Seelze, Germany) and Paraoxon ( $90 \%$, Sigma, Steinheim, Germany) were used for inhibition measurements without additional purification.

\section{Cholinesterase sensor design}

Screen-printed electrodes were produced with the screenprinting 245 DEK machine (Weymouth, England). The working electrodes were manufactured with graphite ink Elektrodag 421 (Acheson Italiana, Milan) on the polyester film Autostat HT5 (Autotype Italia, Milan). The printing 
protocol was described earlier [30]. The diameter of the working electrode was $0.3 \mathrm{~cm}$ and the geometric area was $0.07 \mathrm{~cm}^{2}$.

The modification of screen-printed electrodes with PB was performed as described elsewhere [24]. The electrodes were first pre-activated by polarization at $1.7 \mathrm{~V}$ vs. $\mathrm{Ag} /$ $\mathrm{AgCl}$ for $3 \mathrm{~min}$. Then $5 \mu \mathrm{l}$ of $0.1 \mathrm{~mol} \mathrm{~L}^{-1} \mathrm{~K}_{3} \mathrm{Fe}(\mathrm{CN})_{6}$ in $0.01 \mathrm{~mol} \mathrm{~L}^{-1} \mathrm{HCl}$ were mixed with $5 \mu \mathrm{L}$ of $\mathrm{FeCl}_{3}$ solution of the same concentration and placed onto the working area of the electrodes. After $10 \mathrm{~min}$, the electrodes were washed with $\mathrm{HCl}$ and dried at $100^{\circ} \mathrm{C}$ for $90 \mathrm{~min}$.

ChE was immobilized onto the PB modified electrodes by cross-linking with glutaraldehyde. Prior to immobilization, $2 \mu \mathrm{l}$ of $0.1 \%$ Nafion were pipetted onto the working area of the electrode and allowed to dry. Then a mixture of equal volumes of $0.2 \mathrm{U} \mathrm{mL}^{-1}$ AChE, $1 \%$ BSA, $1 \%$ glutaraldehyde and $0.1 \%$ Nafion was prepared and assigned to electrodes in the amount of $2 \mu \mathrm{L}$ per each one of them. The electrodes were dried to form a protein film on the surface. When investigating immobilization, the above concentrations of the components were varied as mentioned in the text.

\section{Procedures}

Before signal measurement, the $\mathrm{ChE} / \mathrm{PB}$ sensor was equalized at $0.0 \mathrm{~V}$ vs. $\mathrm{Ag} / \mathrm{AgCl}$ for $7 \mathrm{~min}$. After that, the potential of $+200 \mathrm{mV}$ was applied and ATCh added. The current was monitored 3 min adter addition of substrate at $+200 \mathrm{mV}$.

For pesticide determination, the signal was first recorded at the substrate concentration of $1.5 \mathrm{mmol} \mathrm{L}^{-1}$. Then the enzyme sensor was washed and incubated for $10 \mathrm{~min}$ in a pesticide solution. After that, the signal was measured again in the same solution or after replacement of the pesticide solution with a working buffer and the relative decay in the current was calculated in accordance with (4) as a degree of inhibition, $I, \%$.

$I, \%=\frac{i_{o}-i_{t}}{i_{o}} \times 100 \%$

where $i_{o}$ and $i_{t}$ are the current values measured prior to and after the contact of the enzyme sensor with an inhibitor. The incubation period was $10 \mathrm{~min}$ for all the measurements.

Parathion-methyl was pre-oxidized with electrogenerated chlorine before inhibition measurement as described elsewhere [19]. For this purpose, $100 \mu \mathrm{L}$ of Parathionmethyl solution were added to $9.8 \mathrm{~mL}$ of the phosphate buffer solution containing $0.1 \mathrm{~mol} \mathrm{~L}^{-1}$ of $\mathrm{KCl}, \mathrm{pH} 7.8$, and the electrolysis with Pt and glassy carbon electrodes was performed for $5 \mathrm{~min}$ (on-load voltage $6 \mathrm{~V}$ ). Then $100 \mu \mathrm{L}$ of the $2 \%$ formic acid were added and the $\mathrm{pH} 7.4$ was adjusted with $10 \% \mathrm{KOH}$.

The electrolysis of juice with $\mathrm{Al}$ anode was performed as follows. The freshly pressed juice of red or rosé grapes varieties available on the local market was mixed with an equal volume of phosphate buffer solution containing $0.1 \mathrm{~mol} \mathrm{~L}^{-1}$ of $\mathrm{KCl}$. After that, electrolysis with $\mathrm{Al}$ foil (geometric square $1 \mathrm{~cm}^{2}$ ) as anode and glassy carbon cathode was performed for 1-20 min. After the electrolysis, the sediment was removed and $\mathrm{pH}$ value adjusted to 7.4.

For the estimation of pesticide degradation during the wine fermentation, Aldicarb or Paraoxon were used as model pesticides. First, the juice was pressed from white grapes UVA ITALIA EXTRA. Then $2 \mathrm{~g}$ of sugar were dissolved in $20 \mathrm{~mL}$ of water and $100 \mathrm{mg}$ of yeast were added. The suspension was left to stay at $37^{\circ} \mathrm{C}$ for $2 \mathrm{~h}$ and then mixed with $1 \mathrm{~L}$ of grape juice. After $30 \mathrm{~min}$. fermentation, the mixture was divided into three parts $(300,300$ and $400 \mathrm{~mL}$ ). Paraoxon or Aldicarb was added to their final concentration of $500 \mathrm{ppb}$ each to the first and second parts. The third part of the juice $(400 \mathrm{~mL})$ was used as a blank sample. The degree of $\mathrm{ChE}$ inhibition was measured during four days of fermentation at room temperature. For each measurement, the aliquot was taken and centrifuged for 10 min at $6000 \mathrm{rpm}$ and the $\mathrm{pH}$ value of the liquid part was adjusted to 7.40 with $10 \% \mathrm{KOH}$. The degree of inhibition, $I, \%$, was calculated in accordance with (4). The inhibition of pesticides was calculated by eliminating the ethanol contribution estimated in the blank experiments for the same incubation period.

\section{Results and discussion}

The cyclic voltammogram recorded with the PB modified sensor in the presence of free or immobilized ChE contained two connected peaks near $+200 \mathrm{mV}$ corresponding to the coupled oxidation/reduction of the $\mathrm{PB}$ onto the electrode surface. While the ATCh was added, the height of the reduction peak progressively decreased in accordance with the amount of thiocholine taking part in the reaction with the $\mathrm{PB}_{\mathrm{Ox}}$ (see Eq. 3). The optimum conditions as well the evidence for the PB mediation of thiocholine oxidation were established previously and described in [24] for free enzyme. Chemical deposition of rather large amounts of mediator does not allow full disappearance of PB cathodic peak but it can be achieved with lower amounts of reagents taken for $\mathrm{PB}$ formation $\left(0.01 \mathrm{~mol} \mathrm{~L}^{-1} \mathrm{FeCl}_{3}\right.$ and $\left.0.01 \mathrm{~mol} \mathrm{~L}^{-1} \mathrm{~K}_{3} \mathrm{Fe}(\mathrm{CN})_{6}\right)$ at the ATCh concentration of $10 \mathrm{mmol} \mathrm{L}^{-1}$ and higher. It should be mentioned that the changes of the PB current peaks after the substrate addition were found to be milder for immobilized ChE than for free enzyme. This is related to the diffusional limitation of the substrate/product transfer in the surface layer and the low specific enzyme activity chosen to increase the sensitivity of pesticide detection (see discussion below). The immobilization of $\mathrm{ChE}$ did not dramatically affect the position of the peaks on the voltammogramm. Taking into account the value and reproducibility of the signal, the following signal measurements were performed at $+200 \mathrm{mV}$. 


\section{Immobilization Conditions}

The sensitivity of inhibitor determination depends both on the specific activity of an immobilized enzyme and on the reproducibility of the sensor signal. As follows from inhibition kinetics, the lower the enzyme concentration the higher the degree of inhibition measured with the same amount of inhibitor. On the other hand, the decrease in the amount of the enzyme taken for immobilization often results in the losses of its stability and the reproducibility of the signal of enzyme sensor. Hence the decrease in the reproducibility of the signal of enzyme sensor increases the inhibitor concentration which can be measured.

For this reason, the $\mathrm{ChE}$ immobilization conditions were first evaluated. The immobilization mixture contained ChE, BSA, Nafion and glutaraldehyde (see Experimental). The additives provided enzyme stabilization during crossbinding and better adhesion of the layer to the electrode material. In addition, small amounts of BSA increased the efficiency of cross-binding with glutaraldehyde. The ChE itself contains a rather limited number of amino groups on the globule surface so that its reaction with glutaraldehyde without an inert protein is less effective. The dependence of the signal on the ATCh concentration obtained for different enzyme loading is shown on Fig. 1. The response time of enzyme sensor increased with the total protein content from 5-7 to 20-30 s. In general, the decrease in specific enzyme activity and the BSA content resulted in a faster response and a lower stability of the signal measured. The saturation concentration of the substrate in all the cases did not exceed $5 \mathrm{mmol} \mathrm{L}^{-1}$ of ATCh.

The immobilization procedure did not follow significant changes in the $\mathrm{pH}$ dependence of $\mathrm{ChE}$ activity (Fig. 2). The maximum activity at $\mathrm{pH} 8.0$ found was close to that of free ChE. However, because of the low PB stability in basic media the following experiments were carried out at $\mathrm{pH} 7.4$.

To stabilize the low activity of $\mathrm{ChE}$ in the immobilization procedure, it was suggested to place an additional

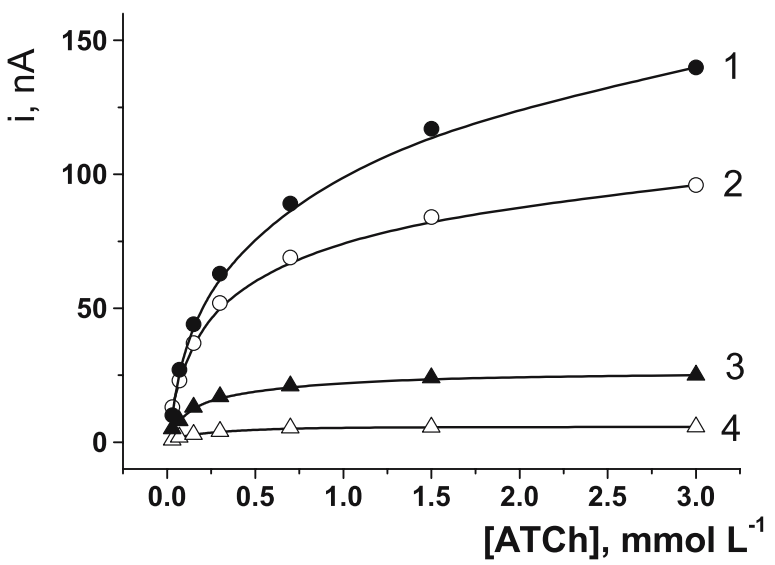

Fig. 1 The dependence of the signal of the ChE/PB sensor on the enzyme loading. Immobilization mixture containes equal volumes of $0.1 \%$ BSA, $1 \%$ glutaraldehyde, $0.1 \%$ Nafion and 0.2 (1) 0.1 , (2) 0.05 (3) 0.02 (4) $\mathrm{U} \mathrm{L} \mathrm{L}^{-1}$ of ChE. $2 \mu \mathrm{L}$ per electrode. ATCh $5.0 \mathrm{mmol} \mathrm{L}^{-1}$, phosphate buffer solution, $\mathrm{pH} 7.4$

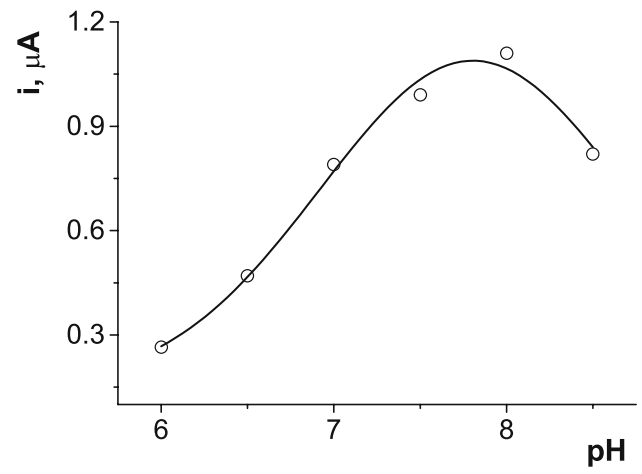

Fig. 2 The $\mathrm{pH}$ dependence of ChE/PB sensor signal. ATCh $1.5 \mathrm{mmol}$ $\mathrm{L}^{-9}$. $0.2 \mathrm{U} \mu \mathrm{L}^{-1}$ of $\mathrm{ChE}$ and $1 \% \mathrm{BSA}$ in immobilization mixture. All the other conditions as desribed in the legend to Fig. 1

Nafion layer onto the electrode modified with PB prior to the immobilization mixture (Fig. 3).

A positive effect of Nafion coating on ChE stability was also observed earlier for non-mediated oxidation of thiocholine and referred to electrostatic interactions within the surface layer [26]. In the presence of the intermediate Nafion layer, the deviation of the signal in six consecutive measurements did not exceed $5.4 \%$. When stored in phosphate buffer solution at $4^{\circ} \mathrm{C}$, the $\mathrm{ChE} / \mathrm{PB}$ sensor lost $15 \%$ of activity in the first two storage days. Then the signal became stable and remained about the same during at least two weeks. After four weeks of storage, about $50 \%$ of the initial enzyme activity was lost. The changes in the signal toward ATCh did not involve significant alteration of the results of inhibition measurements.

The apparent value of Michaelis-Menten constant $\left(K_{m}\right)_{\text {app }}$ calculated from the electrochemical analog of LineweaverBurk equation (5) was found to be $0.84 \pm 0.44 \mathrm{mmol} \mathrm{L}^{-1}$, with the enzyme immobilized onto the electrode and 2.00 \pm $0.84 \mathrm{mmol} \mathrm{L}^{-1}$ when the intermediate Nafion layer was

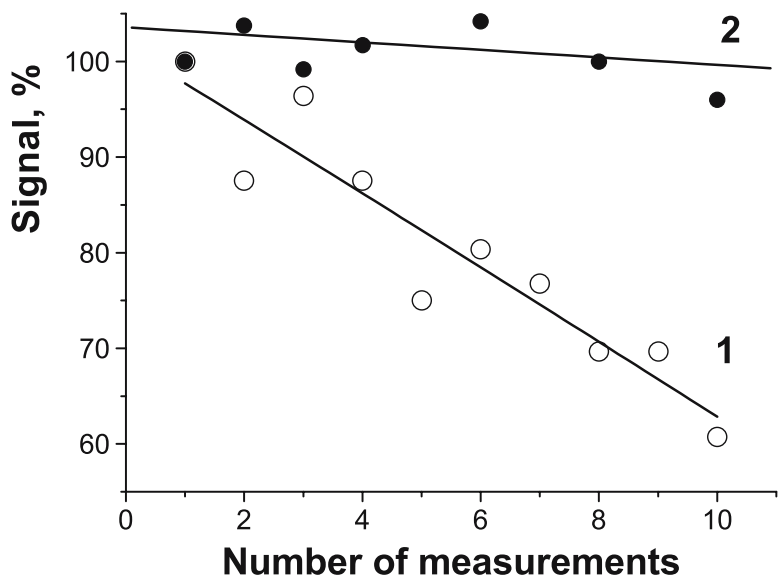

Fig. 3 Relative changes of the initial signal of $\mathrm{ChE} / \mathrm{PB}$ sensor during storage in the phosphate buffer solution, two measurements a day. (1) Without Nafion deposition; (2) with additional Nafion layer on the electrode. $5.0 \mathrm{mmol} \mathrm{L}^{-1}$ ATCh. The content of immobili-

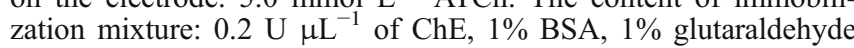
and $0.1 \%$ Nafion 
used. This corresponds to the value obtained with $\mathrm{PB}$ sensor for free enzyme in similar conditions $\left(0.40 \pm 0.12 \mathrm{mmol} \mathrm{L}^{-1}\right)$.

$\frac{1}{i}=\frac{1}{i_{\max }}+\frac{\left(K_{m}\right)_{a p p}}{i_{\max }} \frac{1}{[A T C h]}$

Here $i_{\max }$ corresponds to the saturation current of thiocholine oxidation.

In accordance with the results obtained for various immobilization conditions and from the point of view of signal reproducibility and stability during the storage period, the following content of immobilization mixture was chosen for enzyme sensor development and inhibition measurement: $0.2 \mathrm{U}^{-1} \mathrm{~L}^{-1}$ of ChE, $1 \%$ BSA, $0.1 \%$ Nafion and $1 \%$ glutaraldehyde, ATCh concentration $5.0 \mathrm{mmol} \mathrm{L}^{-1}$, phosphate buffer solution contained $0.1 \mathrm{~mol} \mathrm{~L}^{-1} \mathrm{KCl}, \mathrm{pH}$ 7.4. In these conditions, the $\mathrm{ChE} / \mathrm{PB}$ sensor makes it possible to detect from 0.03 to $5.0 \mathrm{mmol} \mathrm{L}^{-1}$ of ATCh with the response time of less than $10 \mathrm{~s}$. Although lower enzyme loading (down to $0.01 \mathrm{U}$ per electrode) is recommended to use for higher sensitivity of inhibition measurement, this did not provide necessary accuracy of the signal measurement. Probably negatively charged Nafion slightly suppressed the efficiency of enzyme cross-binding with glutaraldehyde in basic media.

Pesticide determination

Thionic pesticides were first oxidized to their phosphoryl analogs by chlorine generated in the electrolysis. In these conditions, Parathion-Methyl is oxidized to phosphoryl product (6). This increased the sensitivity of its determination (Fig. 4).

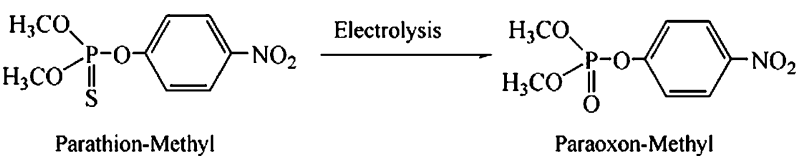

The higher efficiency of Paraoxon-Methyl inhibition determined with the $\mathrm{ChE} / \mathrm{PB}$ sensor is due to the higher affinity of the phosphoryl group to the $\mathrm{ChE}$ binding site in comparison with the thiophosphoryl group of ParathionMethyl. For the following experiments, 5 min electrolysis was performed to achieve the most efficient conversion of the inhibitor. Probably, the excess of chlorine generated in electrolysis can result in additional derivatization of Paraoxon-methyl, e.g. introduction of chlorine atom in aromatic ring. For this reason, the electrolysis products inhibit ChE more effectively than Paraoxon. As was shown previously, the oxidation of thionic pesticides with less active bromine, both chemical and electrochemical, resulted in similar inhibitory activity of Paraoxon and Parathion on immobilized and free $\mathrm{ChE}$ and appropriate calibration graphs were similar to each other [31].
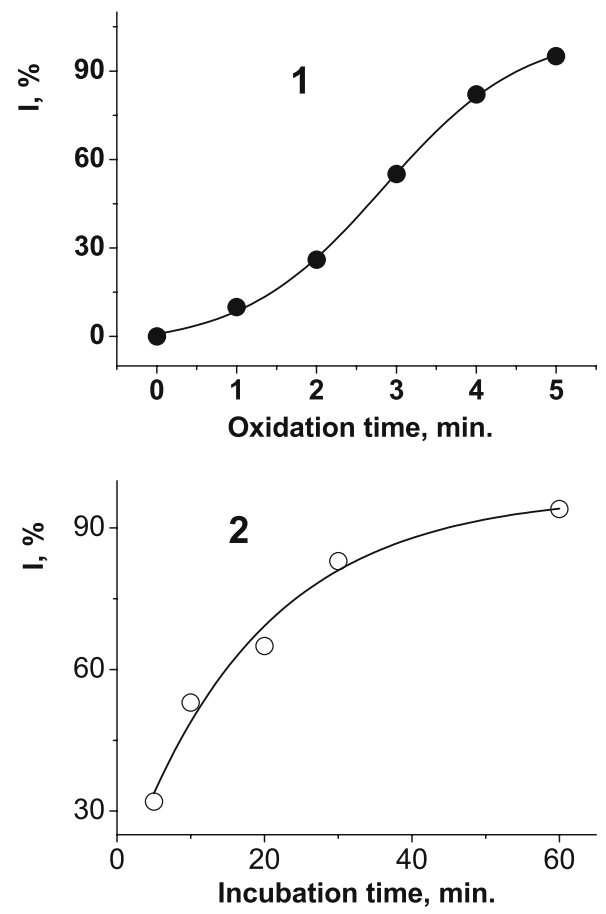

Fig. 4 The influence of measurement conditions on the inhibitory effect of $200 \mathrm{ppb}$ of Parathion-Methyl from model aqueous solution with $\mathrm{ChE} / \mathrm{PB}$ sensor, ATCh $5 \mathrm{mmol} \mathrm{L}^{-1}$. The effect of pre-oxidation (1) and incubation periods (2)

Aldicarb and Paraoxon were tested with the ChE/PB sensor withoHut any pre-treatment.

All the pesticides investigated exerted strongly irreversible inhibition of ChE. The mechanism of inhibition was proved by the dependence of the degree of inhibition (I,\%) on the incubation time (Fig. 4 for Paraoxon-Methyl).

The appropriate calibration curves are linearized in the plots of $I, \%$, against $\log [$ Pesticide]. The analytical characteristics of inhibitor determination are summarized in the Table 1. The limit of detection corresponds to the amount of an inhibitor which leads to the decrease of the signal equal to the triplicate error of the signal measurement. The concentration range of pesticide to be determined corresponds to linear piece of calibration curve. The inhibition and the following signal detection were performed in the same solution. First the pesticide solution was added and

Table 1 The coefficients of calibration curves $I(\%)=\mathrm{a}+\mathrm{b} \times \log$ [Pesticide, ppb], detection of limits and range of pesticide concentration determined with $\mathrm{ChE} / \mathrm{PB}$ sensor

\begin{tabular}{|c|c|c|c|}
\hline Pesticide & Aldicarb & Paraoxon & Parathion-methyl \\
\hline Slope (b) & $66.5 \pm 2$ & $70 \pm 2$ & $135 \pm 6$ \\
\hline Intercept (a) & $-99 \pm 4$ & $-64 \pm 3$ & $-94 \pm 6$ \\
\hline Correlation coefficient & 0.9989 & 0.9991 & 0.9982 \\
\hline Limit of detection, ppb & 30 & 10 & 5 \\
\hline Range of concentration, ppb & $38-380$ & $14-173$ & $7-26$ \\
\hline
\end{tabular}

Incubation $10 \mathrm{~min}$ 
then in $10 \mathrm{~min}$ (incubation time) the substrate $\left(5 \mathrm{mmol} \mathrm{L}{ }^{-1}\right.$ ATCh) was injected. The excess of ATCh stopped the interaction of the enzyme and the inhibitor due to the formation of an enzyme-substrate complex which could not react with the pesticide. The sensitivity obtained with this procedure was about the same as that obtained using two different solutions. In this latter case, after incubation, the sensor was moved into a new buffer solution where the substrate was added and signal measured. This procedure is particularly appropriate and important because of the possibility to detect pesticides in complex media that do not allow direct measurements of thiocholine oxidation.

The following improvement of pesticide detection can be achieved by increasing incubation time. However this was followed with decrease in the efficiency of ChE reactivation and with lower accuracy of inhibition measurement. Taking into account the requirements related to field application of enzyme sensors, all the following experiments were performed with $10 \mathrm{~min}$ incubation. In these conditions, relative standard deviation of the pesticide determination with $\mathrm{ChE} / \mathrm{PB}$ sensor did not exceed $12 \%$.

After the inhibition, the $\mathrm{ChE} / \mathrm{PB}$ sensor could be treated with $0.1 \% 2$-PAM for $10 \mathrm{~min}$ to reactivate the enzyme. If the inhibition did not exceed $60 \%, 100 \%$ reactivation of the signal was achieved. However, the reactivation irregularly suppressed the sensitivity of the following inhibition measurements. For this reason, the results summarized in the Table 1 were obtained with single-use ChE/PB sensors. Each point corresponded to the average results obtained with three disposable $\mathrm{ChE} / \mathrm{PB}$ sensors prepared on time.

In comparison with literary data, the use of the PB modified transducer resulted in the improvement of the characteristics of pesticide detection. Thus, the following detection limits of Paraoxon were obtained with the help of various detection systems: $23 \mathrm{ppb}$ (field-effect transistors and microconductometric devices [32], $120 \mathrm{ppb}$ (Co phtalocyanine modified carbon electrode [27]). The higher sensitivity toward Paraoxon was reached by specific sample treatment, i.e. flow-through mode [33] or by the use of organic solvents [34]. For this purpose, the increasing incubation time (up to one hour) was also used. Genetically engineering of acetylcholinesterases also provided improved sensitivity toward Paraoxon [35]. The ChE conductometric sensor was used for the estimation of the rate of photodegradation of Parathion-Methyl [36]. The limit of detection of Parathion-Methyl reported (2 ppm) could be related rather to the traces of the oxidized analog because no specific procedures for its oxidation to the oxon form were mentioned. The unexpected difference in the characteristics of inhibition observed for Parathion-Methyl and Paraoxon can be related to the oxidation procedure suggested. The exhaustive amounts of chlorine generated in electrolysis.

For Aldicarb, the limit of detection of $40 \mathrm{ppb}$ was obtained with the ChE - ChO bi-enzyme sensor and the $\mathrm{Pt}$ amperometric transducer [37] and about $10 \mathrm{ppb}$ with the ChE sensor based on screen-printed electrodes, with Co phtalocyanine implemented in carbon paste [28].
Pesticide degradation monitoring during wine fermentation

Anticholinesterase pesticides are widely used in the production of table and wine grapes [38]. About 20 organophosphates and carbamates are allowed for application in wine growing in EU countries with the average application rate of about $1 \mathrm{~kg} \mathrm{ha}^{-1}$. The maximum permissible levels of pesticides in wine grapes in harvesting are established at the level of $0.1-0.5 \mathrm{mg} \mathrm{kg}^{-1}$. Although more than $80 \%$ of pesticides decompose in fermentation conditions, the influence of pesticides on grape fermentation and wine quality is a matter of concern. Thus, the significant influence of Parathion and Chloropyrifos-methyl on the yeast growth was mentioned [39]. Anticholinesterase pesticides are spontaneously hydrolyzed in the environment to the non-toxic products. However, the rate of this process is highly affected by matrix features. In some vegetables and ground waters the residuals of pesticides are detectable for several months after contamination [40]. The fate of the pesticides in the fermentation is still unclear but can be assumed in a similar way [41].

First, the inhibition was measured in freshly pressed juice spiked with the pesticides. The juice was diluted twice with buffer solution, then the substrate was added in $10 \mathrm{~min}$ and the signal recorded as described above for model pesticide solution. However, a high background current did not allow reaching the necessary accuracy of signal measurement directly in diluted juice. Moreover, 10 min contact with the juice freshly pressed from red and rosé grapes varieties caused an irreversible decrease of the ATCh signal by $20-30 \%$ due to the matrix effect on enzyme activity. The matrix influence is aggravated during fermentation due to the accumulation of ethanol in the sample tested.

To overcome the matrix interference, two procedures were tested, i.e. the removal of readily oxidized compounds and the partial evaporation of volatile components under vacuum. In the first case, the electrolysis of juice was performed with aluminum anode. The partial dissolution of anode resulted in the formation of insoluble phenolic complexes followed by their precipitation together with aluminum hydroxide in weakly basic media $(\mathrm{pH} 7.4)$ [42]. Indeed, the electrolysis resulted in a sufficient decrease of the background current. The inhibition caused by matrix components also became lower and reversible (Fig. 5).

The washing of the ChE/PB sensor with working buffer solution after its 10 min contact with treated juice resulted in recovery of $60-70 \%$ of the initial response. However, even in the presence of additional amounts of chlorides the electrolysis of spiked juice showed low efficiency of oxidation of thionic pesticides. Probably, anodic Al dissolution remained the main electrochemical reaction and the generation of chlorine did not promote thiophosphate oxidation. As a result, the Parathion-Methyl inhibition was found to be 3-4 times lower than that in the model aqueous solution. Electrolysis can also promote non-enzymatic 

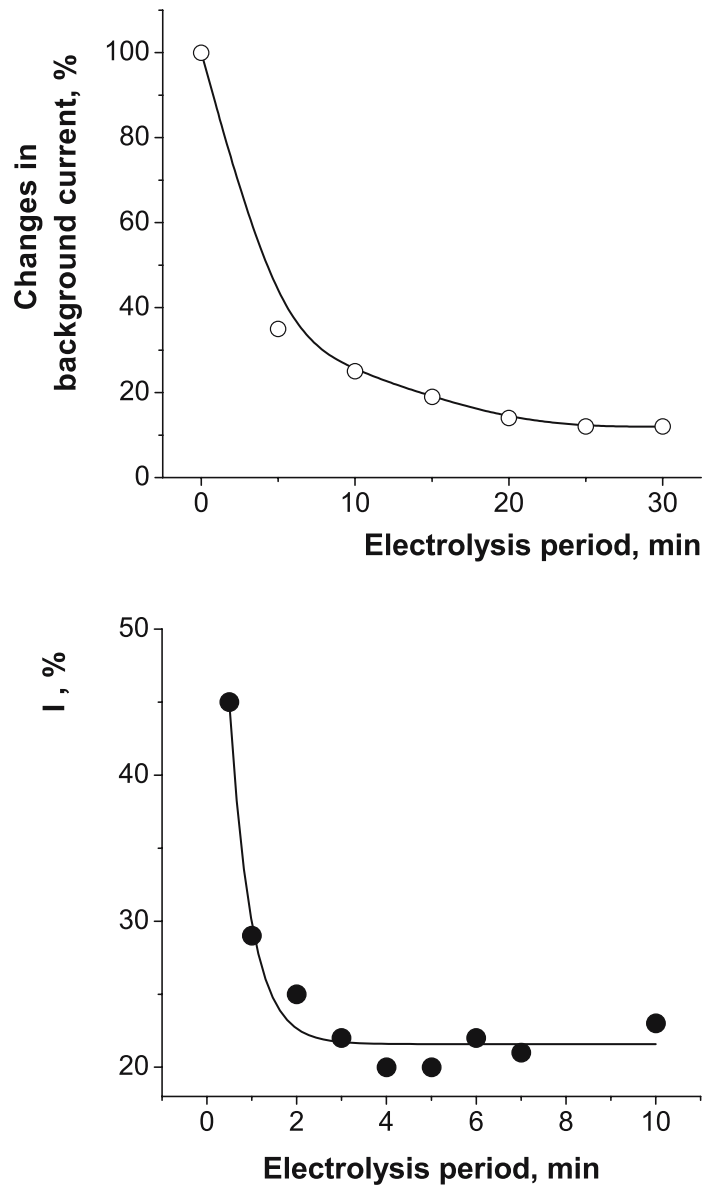

Fig. 5 The influence of electrolysis with soluble Al anode on the background current (1) and the inhibition of $200 \mathrm{ppb}$ of ParathionMethyl (2) observed in juice from red grapes

hydrolysis of anticholinesterase pesticides and their removal with the sediments. This was proved by the decrease of inhibition of Aldicarb which did not require electrochemical pre-activation. The limits of detection obtained after the electrolysis of diluted juice with $\mathrm{Al}$ anode were equal to $0.1 \mathrm{ppm}$ for Parathion-Methyl and $1 \mathrm{ppm}$ for Aldicarb (all the concentrations are given for undiluted juice). This is near the maximum admissible levels for wine grapes. Nevertheless, the sample treatment proposed can be recommended only for testing moderate and high levels of pollution because of the rather low stability of the pesticides in these conditions. After electrolysis, the anticholinesterase activity of spiked juice progressively decreased to $20-30 \%$. The latter values corresponded to the matrix influence observed in the same juice with no pesticide added.

The evaporation of volatile compounds was performed to take into account the possible effect of ethanol formed in fermentation. $10-15 \%$ of ethanol $(\mathrm{v} / \mathrm{v})$ was added to the juice prior to evaporation to simulate fermentation process. If the juice did not contain any pesticides, the evaporation decreased the inhibition caused by ethanol from $80-100 \%$ to $40-45 \%$. However, this procedure did not allow avoiding interferences with the pesticide inhibition related to the phenolic compounds present in the matrix. As in freshly

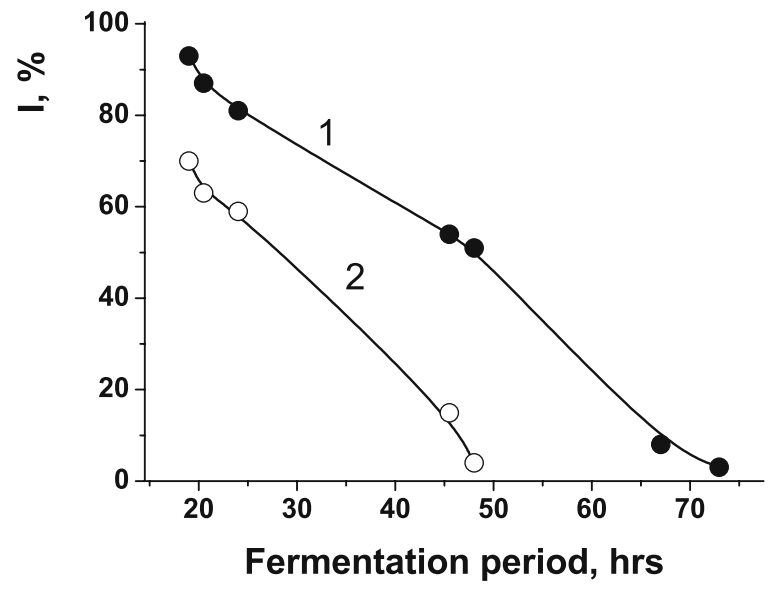

Fig. 6 The degree of inhibition measured in the fermentation process of white grape juice spiked with 500 ppb of Paraoxon (1) and $500 \mathrm{ppb}$ of Aldicarb (2)

pressed juice, the background current and non-specific inhibition hinder the accurate measurement of the signal and inhibition calculation.

After that, the detection of pesticide residues in wine was performed with the method previously suggested for juice testing. For this purpose, either Aldicarb or Paraoxon were added to grape juice at the beginning of wine fermentation. The ChE/PB sensor was incubated for $10 \mathrm{~min}$ and then moved to the standard buffer solution for signal measurement. Thus, the matrix components interfering with signal measurement did not contact with the electrode after the inhibition step. ChE provided the selective extraction of the pollutants and their quantification as described above for the model solutions. Blank and spiked samples of juice under fermentation were tested without any additional dissolving. No spontaneous reactivation of inhibited $\mathrm{ChE}$ was observed in the measurement conditions. The results of the monitoring of pesticide degradation are shown on Fig. 6. The Paraoxon and Aldicarb life-time was estimated as three and two days, respectively. The decay in the inhibition during the fermentation can be also due to interaction of pesticides with matrix components, however the tendency in inhibition changes correspond to the reported HPLC estimation of pesticides residues in wine and fermentation media [41, 43, 44]. In accordance with them, about $90 \%$ of initial amounts of pesticides tested decomposed in the first three days of fermentation.

\section{Conclusions}

The modification of the screen-printed electrode with PB provided significant improvement in the performance of the ChE/PB sensor. This was revealed in the decrease of the working potential of thiocholine oxidation and in the fast and reliable response toward a specific substrate, ATCh. The stability of the signal as well as its value depend on the content of the protein layer formed in the immobilization procedure. The variation of the additives 
and their quantities, i.e. BSA and Nafion, made it possible to stabilize the behavior of the $\mathrm{ChE} / \mathrm{PB}$ sensor both during storage and the consecutive measurements with the same substrate solution. The improved characteristics of substrate detection are accompanied by a rather high sensitivity of the detection of anticholinesterase pesticides, even in a complicated matrix, e.g. grape juice and wine during fermentation. The limits of detection obtained are small enough to detect the trace amounts of anticholinesterase pesticides on the level of their admissible concentrations in wine grapes or soil. Taking into account the accuracy of signal measurement and the variation of the matrix content, $\mathrm{ChE} / \mathrm{PB}$ sensor can be used for semi-quantitative estimation of pesticide traces in grapes and must and for preliminary testing of contaminant level in field.

The pesticide detection is complicated with the interfering effect of phenolic compounds and ethanol formed in fermentation. Their effect is progressively increased during first two days of fermentation. For highly contaminated samples, the interfering influence of matrix components can be partially removed by electrolysis with soluble $\mathrm{Al}$ anode. However, the decrease in the influence of phenolic compounds is followed by partial destruction of pesticides. For this reason, direct measurements of pesticide inhibition in grape juices and wine can be recommended for rather highly contaminated samples and at the beginning of fermentation.

Acknowledgements Financial support of INTAS (grant No 00273 ) is gratefully acknowledged. The authors thank Prof. A.A. Karyakin (Moscow State University) for suggestions concerning the $\mathrm{PB}$ application in the sensor assembly.

\section{References}

1. Wang J (2000) Analytical electrochemistry, 2nd edn. Wiley$\mathrm{VCH}$

2. Katakis I, Dominguez E (1995) Trends Anal Chem 14:310

3. Albareda-Sirvent M, Merkoçi A, Alegret S (2000) Sens Actuators B 69:153

4. Hart JP, Wring SA (1997) Trends Anal Chem 16:89

5. Chaubey A, Malhotra BD (2002) Biosens Bioelectron 17:441

6. O'Halloran MP, Pravda M, Guilbault GG (2001) Talanta 55:605

7. Danilowicz C, Corton E, Battaglini F, Calvo EJ (1998) Electrochim Acta 43:3525

8. Palmisano F, Zambonin PG, Centonze D (2000) Fresenius J Anal Chem 366:586

9. Cosnier S (1999) Biosens Bioelectron 14:443

10. Mulchandani A, Pan S (1999) Anal Biochem 267:141

11. Mao L, Yamamoto K (2000) Talanta 51:187

12. Karyakin AA, Karyakina EE (1999) Sens Actuators B 57:268
13. de Mattos IL, Gorton L, Ruzgas T, Karyakin AA (2000) Anal Sci 16:795

14. Ricci F, Amine A, Tuta CS, Ciucu AA, Lucarelli F, Palleschi G, Moscone D (2003) Anal Chim Acta 485:111

15. Qijin C, Shaojun D (1995) Anal Chim Acta 310:429

16. Garjonyte R, Malinauskas A (2000) Biosens Bioelectron $15: 445$

17. Lu W, Wallace GG, Karayakin AA (1998) Electroanalysis $10: 472$

18. Wu XQ, Guo XM, Wang R, Zhang ZR (2001) Chinese J Anal Chem 29:1273

19. Ivanov A, Evtugyn G, Budnikov H, Ricci F, Moscone D, Palleschi G (2003) Anal Bioanal Chem 377:624

20. Dong SJ, Che GL (1991) J Electroanal Chem 315:191

21. Hou WY, Wang E (1992) Anal Chim Acta 257:275

22. Scharf U, Grabner EW (1996) Electrochim Acta 41:233

23. Wilkins E, Carter M, Voss J, Ivnitski D (2000) Electrochem Commun 2:786

24. Ricci F, Arduini F, Amine A, Moscone D, Palleschi G (2004) J Electroanal Chem 563:229

25. Rehak M, Snejdarkova M, Hianik T (1997) Electroanalysis 9:1072

26. Gogol EV, Evtugyn GA, Marty JL, Budnikov HC, Winter VG (2000) Talanta 53:379

27. Skládal P, Mascini M (1992) Biosens Bioelectron 7:335

28. Nunes GS, Skládal P, Yamanaka H, Barcelo D (1998) Anal Chim Acta 362:59

29. Martorell D, Cespedes F, Martinez-Fabregas E, Alegret S (1997) Anal Chim Acta 337:305

30. Ricci F, Amine A, Palleschi G, Moscone D (2003) Biosens Bioelectron 18:165

31. Evtyugin GA, Stoikova EE, Iskanderov RR, Nikol'skaya EB, Budnikov GK (1997) Russ J Anal Chem (Moscow) 52:2

32. Jaffrezic-Renault N, Martelet C, Clechet P, Nyamsi Hendji AM, Schul'ga AA, Dzyadevich SV, Soldatkin AP, Nechiporuk LI (1996) Sensors Materials 8:161

33. Jeanty G, Marty JL (1998) Biosens Bioelectron 13:213

34. Fennouh S, Casimiri V, Burstein C (1997) Biosens Bioelectron 12:97

35. Bachmann TT, Leca B, Vilatte F, Marty JL, Fournier D, Schmid RD (2000) Biosens Bioelectron 15:193

36. Dzyadevych SV, Soldatkin AP, Chovelon JM (2002) Anal Chim Acta 459:33

37. Bernabei M, Cremisini C, Mascini M, Palleschi G (1991) Anal Lett 24:1317-1332

38. FAO (2002) Submission and Evaluation of Pesticide Residues Data for the Estimation of Maximum Residue Levels in Food and Feed, 1 st edn. FAO, Rome

39. Sharma J, Satya S, Kumar V, Tewary DK (2005) Chem Health Safety $12: 17-22$

40. Basanta R, Nunez A, Lopez E, Fernandez M, Diaz-Fierros F (1995) Intern J Environmenal Studies 48:211

41. Corbett JR (1974) The Biochemical Mode of Action of Pesticides, Academic Press, London

42. Phutdhawong W, Chowwanapoonpohn S, Buddhasukh D (2000) Anal Sci 16:1083-1086

43. Ruediger GA, Pardon KH, Sas AN, Golden PW, Pollnitz AP (2005) J Agric Food Chem 53:3023

44. Cabras P, Angioni A (2000) J Agriculture Food Chem 48:967 